\title{
Attenuation of the aversive and analgesic effects of morphine by repeated administration: Different mechanisms
}

\author{
MICHAEL DOMJAN \\ University of Texas, Austin, Texas \\ and \\ SHEPARD SIEGEL \\ McMaster University, Hamilton, Ontario, Canada
}

\begin{abstract}
Rats were repeatedly injected with a low $(8 \mathrm{mg} / \mathrm{kg})$ or high $(40 \mathrm{mg} / \mathrm{kg})$ dose of morphine during the preexposure phase of the experiment. They then received both taste-aversion training and morphine-induced analgesia assessment. These tasks were presented in the same environment or in a different environment from that associated with the drug during preexposure. Morphine preexposure attenuated morphine-induced taste aversion conditioning, whether or not the conditioning was conducted in the same environment as morphine preexposure. In contrast, the display of analgesic tolerance was more pronounced in the preexposed environment than in the alternative environment. These results suggest that repeated morphine administrations attenuate the aversive and analgesic effects of the drug by different mechanisms.
\end{abstract}

Learned taste aversions, although typically acquired rapidly, are sensitive to disruption by several manipulations, including preconditioning exposure to the unconditioned stimulus (US). One prominent account of the US preexposure effect attributes the phenomenon to acquisition of competing associations (Randich \& LoLordo, 1979). According to this explanation, contextual cues become associated with the US during the course of repeated preconditioning presentations and "block" conditioning of the taste cue during subsequent taste-US pairings (Kamin, 1969). The blocking interpretation implies that interference with taste-aversion conditioning will be limited to the environmental context in which preconditioning presentations of the US are administered. Results confirming this prediction have been frequently reported (Batson \& Best, 1979; Braveman, 1979; Decanay \& Riley, 1982; Domjan \& Best, 1980).

The situation specificity of US preexposure effects on taste aversion learning is similar to observations of situation specificity of drug tolerance (e.g., Siegel, 1976). In both cases, repeated administrations of a drug reduce the subsequent effects of the drug as long as circumstances of drug administration are not

This research, supported by a grant from the Natural Sciences and Engineering Research Council of Canada to S. Siegel, was conducted at McMaster University while M. Domjan was on sabbatical leave there from the University of Texas. The assistance of Doreen Mitchell is gratefully acknowledged. Requests for reprints should be sent to M. Domjan, Department of Psychology, University of Texas at Austin, Austin, Texas 78712. changed. Siegel has suggested that such phenomena are mediated by drug compensatory responses that become conditioned to cues reliably paired with drug administration. The effect of a drug administered in the context of these cues, but not in the context of alternative cues, is attenuated by this anticipatory compensation (see review by Siegel, 1983).

The conditioning model provides an attractive mechanism for the blocking interpretation of the US preexposure effect in taste aversion conditioning. However, most of the evidence for the situational specificity of tolerance has been obtained in experiments with morphine, whereas evidence for the situational specificity of the US preexposure effect in taste aversion learning has been obtained with lithium. Studies, with morphine, of the effects of context alterations between preexposure and taste aversion learning are required to determine whether the conditioning model is relevant to the US preexposure effect. Two such experiments have been recently published (Dacanay \& Riley, 1982; Setwart \& Eikelboom, 1978). Both found that environmental manipulations did not influence the magnitude of the detrimental effect of morphine preexposure on subsequent saccharin-morphine associations.

The above studies suggest that attenuation of the aversive and analgesic effects of morphine by repeated administrations is mediated by different mechanisms. However, only one study incorporated both taste-aversion and analgesia tests in same experiment (Stewart \& Eikelboom, 1978, Experiment 2). Evidence of the situation specificity of analgesic 
tolerance in this experiment was confounded by practice with the analgesia assessment procedure, and only one dose of morphine was used. The present study was designed to assess the situation specificity of repeated morphine administrations on subsequent morphine-induced taste-aversion learning and analgesia at two drug doses ( 8 and $40 \mathrm{mg} / \mathbf{k g}$ ), with none of the subjects receiving practice with the analgesia assessment procedure prior to the analgesia test session.

\section{METHOD}

\section{Subjects and Drug Preexposure}

Forty-eight, experimentally naive, male, Sprague-Dawley rats, 200-225 g at the start of the experiment, were individually housed with continuous access to food and 20-min daily access to water. Three weeks after the initiation of water deprivation, groups of rats were preexposed to morphine in one of two distinctive environments: the home cage in which they were housed (individual, suspended, wire-mesh cages, $26 \mathrm{~cm}$ long $\times 17 \mathrm{~cm}$ high, in the colony room) or an alternative environment (individual clear plastic cages, $34 \times 28 \times 15 \mathrm{~cm}$, with wood shaving bedding, located in a different room in which there was continuous white noise at $75 \mathrm{~dB}$ SPL). During the preexposure phase, the rats received five alternating sessions in each environment, with morphine administered in one environment and physiological saline in the other environment. On each preexposure day, food was unavailable for $60 \mathrm{~min}$, commencing with the 20-min drinking period. Immediately following the water-access period, the subjects were injected with either morphine or physiological saline (in, respectively, the drugassociated and saline-associated environments). For half the morphine-preexposed rats, the morphine dose was $8 \mathrm{mg} / \mathrm{kg}$, and for the other half, the dose was $40 \mathrm{mg} / \mathrm{kg}$ (ip, of a $40-\mathrm{mg} / \mathrm{ml}$ solution of morphine sulfate). A third, nonpreexposed, group received five sessions in each of the two environments, but all 10 preexposure injections consisted of physiological saline. The interval between preexposure sessions alternated between 2 and 4 days (between sessions, the subjects received the 20-min water access period but were otherwise undisturbed).

\section{Taste-Aversion Training}

Following preexposure, all rats received five taste-aversion trials. Half the rats preexposed to each dose of morphine in each environment received saccharin-morphine pairings in the morphine-paired environment (Same-Px), and half received the pairings in the saline-associated environment (Diff-Px). The same dose of morphine used during preexposure was also used during taste-aversion learning. Nonpreexposed rats (No-Px) received taste-aversion training in one of the two environments with one of the two drug doses. At both dose levels, each of Groups Same-Px, Diff-Px, and No-Px contained eight subjects. For each tasteaversion session, food was removed, the rats received a .1\% solution of sodium saccharin for 20 min (rather than water), the drug was injected, and, 40 min later, food was replaced.

\section{Analgesia Assessment}

Five to 7 days after the last saccharin trial, the 16 nonpreexposed subjects were tested for morphine-induced analgesia, using the hot plate procedure (Fennessy \& Lee, 1975). The rats were injected with morphine $(8 \mathrm{mg} / \mathrm{kg})$ immediately after drinking water for $20 \mathrm{~min}$. Thirty and $45 \mathrm{~min}$ after the morphine injection, each subject was placed on a copper plate maintained at $54^{\circ} \mathrm{C}$ and was allowed to remain there until it licked one of its paws. Half of the subjects received the 20 -min access to water and morphine injection in the same environment in which saccharin conditioning had been conducted, and the remaining subjects received the treatments in the alternate environment.

\section{RESULTS AND DISCUSSION}

\section{Preexposure}

During preexposure trials, morphine injections were administered after the subjects had drunk water. This procedure did not significantly affect water intake. Mean water intakes of the low- and high-dose groups during the first morphine preexposure trial were 18.2 and $17.8 \mathrm{ml}$, respectively. During the fifth (last) morphine preexposure trial, mean intakes were 17.6 and $19.9 \mathrm{ml}$.

\section{Taste-Aversion Learning}

The amount of saccharin ingested by subjects in the various groups during the taste-aversion phase of the experiment is summarized in Figure 1. With both doses of morphine, nonpreexposed subjects showed progressive decrements in saccharin consumption between Trials 1 and 4, followed by a small increase on Trial 5. Progressive decreases in saccharin intake were not observed in subjects that had been preexposed to morphine. In fact, these groups increased their saccharin intake between Trials 1 and 5. Furthermore, similar results occurred whether or not saccharin conditioning was given in the same environment as morphine preexposure. No significant differences between Groups Same-Px and Diff-Px were found on any saccharin trial with either the low or the high dose of morphine. These results confirm previous reports that the deleterious effect of morphine preexposure on flavor-morphine aversion learning is not attributable to the acquisition of an environment-drug association during preexposure (Dacanay \& Riley, 1982; Stewart \& Eikelboom, 1978).

With the low dose of morphine, Group Diff-Px drank significantly more saccharin than Group NoPx on each of Trials 2-5 (Us < 15.5; ps < .05), and Group Same-Px drank significantly more saccharin than Group No-Px on Trials 4 and 5 (Us $<8$, ps $<.005)$. With the high dose of morphine, Group Diff-Px drank significantly more saccharin than Group No-Px on each of Trials 2-5 (Us $<14.5$, ps $<$ $.05)$ and Group Same-Px drank more saccharin than Group No-Px on each of Trials 3-5 (Us $<11.5$, ps $<$.02).

\section{Analgesia Assessment}

No significant differences in paw-lick latency were observed between animals tested in the same and different environments 30 min after the morphine injection (means $=15.3$ and $12.7 \mathrm{sec}$, respectively; $\mathrm{U}=$ 19). However, 45 min after the morphine administration, the animals tested in the same environment in 


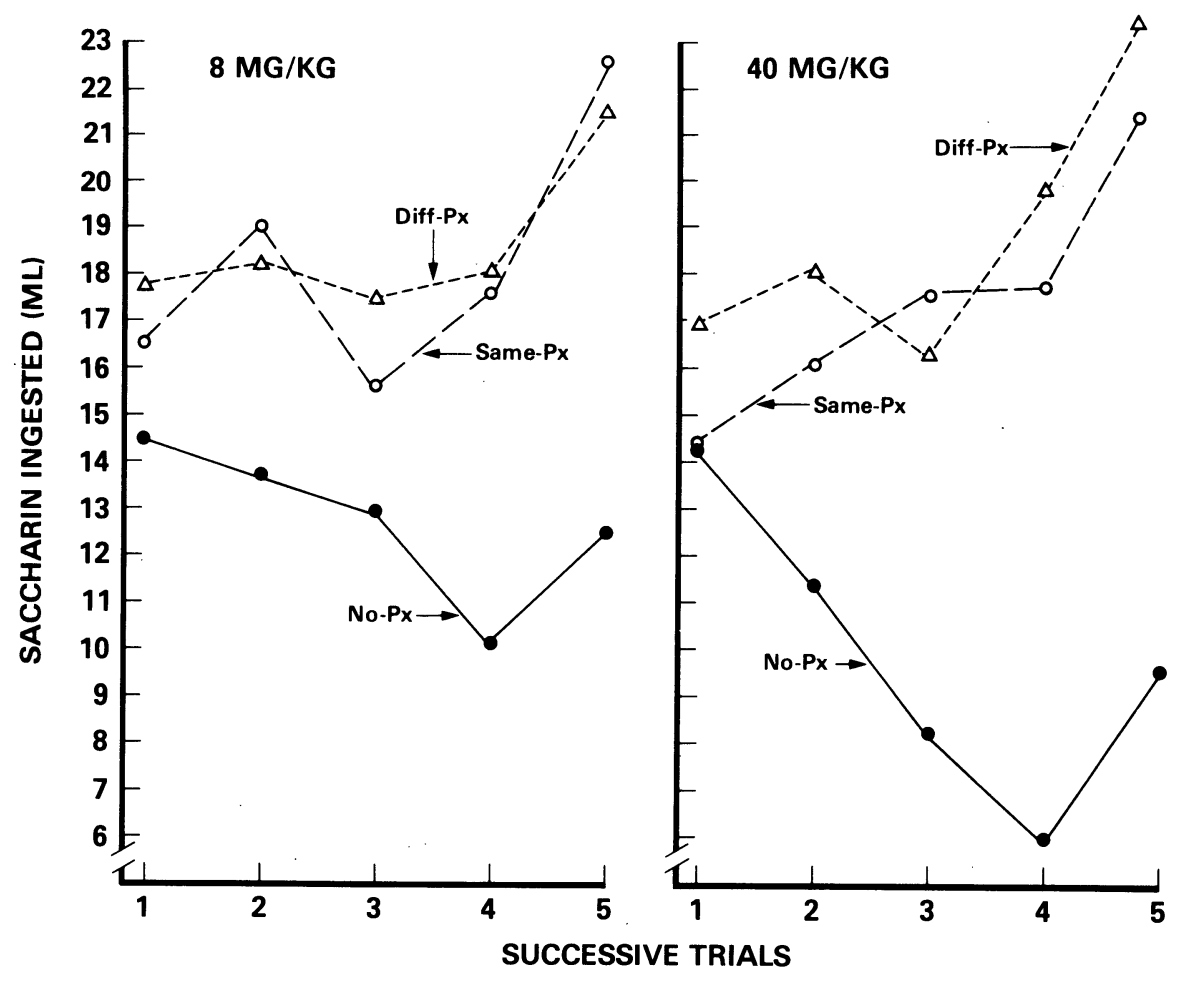

Figure 1. Mean amounts of saccharin ingested by independent groups of rats during successive taste-aversion trials following no morphine preexposure (No-Px) or morphine preexposure in the same environment as taste conditioning (Same-Px) or in a different environment (Diff-Px). (For some animals, the dose of morphine was always $8 \mathrm{mg} / \mathrm{kg}$; for others, it was always $40 \mathrm{mg} / \mathrm{kg}$.)

which they had received saccharin conditioning evidenced significantly less morphine-induced analgesia (paw-lick latency $=5.9 \mathrm{sec}$ ) than did the animals tested in the alternate environment (paw-lick latency $=16.8 \mathrm{sec} ; \mathrm{U}=9, \mathrm{p}<.01)$. These results indicate that the subjects were able to discriminate between the home cages and distinctive environments. The results are also consistent with the assumption that an environment-drug association contributes to morphine analgesic tolerance (see Siegel, 1983).

The situation specificity of morphine effects observed when subjects were tested for analgesic tolerance on the hot plate confirms previous demonstrations of this effect (e.g., Siegel, 1976) and contrasts with the absence of situation specificity of morphine preexposure on taste-aversion conditioning. These findings suggest that several different mechanisms are activated by repeated morphine administrations. Numerous experiments have shown, consistent with the present findings, that drug compensatory responses become conditioned to environmental cues predictive of morphine administration and lead to situation specificity of tolerance to the analgesic effects of morphine (see review by Siegel, 1983). Such conditioned compensatory responses are evidently not responsible for the effects of US preexposure on morphine-induced taste-aversion learning.
The absence of situation specificity of morphine preexposure effects on taste-aversion learning contrasts with observations of situation specificity in US preexposure experiments conducted with lithium (Batson \& Best, 1979; Braveman, 1979; Dacanay \& Riley, 1982; Domjan \& Best, 1980). These diverse results indicate that disruptions of taste-aversion learning produced by US preexposure can be mediated by several different mechanisms. An associative interference or blocking interpretation is consistent with the results of preexposure to lithium but not with the results of preexposure to morphine. Further work is required to isolate the critical mechanism for morphine preexposure effects.

\section{REFERENCES}

Batson, J. D., \& Best, M. R. Drug-preexposure effects in flavor-aversion learning: Associative interference by conditioned environmental stimuli. Journal of Experimental Psychology: Animal Behavior Processes, 1979, 5, 273-283.

Braveman, N. S. The role of blocking and compensatory conditioning in the treatment preexposure effect. Psychopharmacology, 1979, 61, 177-189.

Decanay, R. J., \& RiLeY, A. L. The UCS preexposure effect in taste aversion learning: Tolerance and blocking are drug specific. Animal Learning \& Behavior, 1982, 10, 91-96.

DomJAn, M., \& BEST, M. R. Interference with ingestional aversion learning produced by preexposure to the unconditioned 
stimulus: Associative and nonassociative aspects. Learning and Motivation, 1980, 11, 522-537.

Fennessy, M. R., \& LeE, J. R. The assessment of and the problems involved in the experimental evaluation of narcotic analgesics. In S. Ehrenpreis \& A. Neidle (Eds.), Methods in narcotics research. New York: Marcel Dekker, 1975.

KAMIN, L. J. Predictability, surprise, attention, and conditioning. In B. A. Campbell \& R. M. Church (Eds.), Punishment and aversive behavior. New York: Appleton-Century-Crofts, 1969.

RANDICH, A., \& LoLoRDo, V. M. Associative and nonassociative theories of the UCS preexposure phenomenon: Implications for Pavlovian conditioning. Psychological Bulletin, 1979, 86, 523-548.
Siegel, S. Morphine analgesic tolerance: Its situation specificity supports a Pavlovian conditioning model. Science, 1976, 193, 323-325.

Siegel, S. Classical conditioning, drug tolerance, and drug dependence. In Y. Israel, F. B. Glaser, H. Kalant, R. E. Popham, W. Schmidt, \& R. G. Smart (Eds.), Research advances in alcohol and drug problems (Vol. 7). New York: Plenum, 1983.

Stewart, J., \& Eikelboom, R. Pre-exposure to morphine and the attenuation of conditioned taste aversion in rats. Pharmacology Biochemistry \& Behavior, 1978, 9, 639-645.

(Manuscript received March 8, 1983; revision accepted for publication May 25, 1983.) 